\title{
THE INFLUENCE OF CHLORPROMAZINE HYDROCHLORIDE ON THE SIZE OF SMALL UNILAMELLAR DIMYROSTYLPHOSPHATIDYLCHOLINE LIPOSOMES AS REVEALED BY LIGHT SCATTERING PHOTOMETRY
}

\author{
FARAH HAMAD FARAH \\ Department of Pharmaceutical Sciences, College of Pharmacy and Health Sciences, Ajman University, Ajman, United Arab Emirates \\ Email: f.hamad@ajman.ac.ae
}

Received: 16 Feb 2019, Revised and Accepted: 11 Apr 2019

\begin{abstract}
Objectives: This study aims to investigate the possible influence of the model, cationic, surface-active solute chlorpromazine hydrochloride (CPZ$\mathrm{HCl}$ ) on the size of small unilamellar dimyristoyl phosphatidylcholine (DMPC) liposomes as a function of temperature and CPZ-HCl concentration, below and above the critical micelle concentration (CMC).

Methods: Small unilamellar DMPC liposomes were prepared by dissolving DMPC in chloroform and the solvent was rota-evaporated in a water bath adjusted at $40{ }^{\circ} \mathrm{C}$. The lipid film was then dispersed in $0.1 \mathrm{M} \mathrm{KCl} \mathrm{solution} \mathrm{adjusted} \mathrm{at} \mathrm{pH} 6.2$ to form large multilamellar liposomes which are then sonicated and fractionated via Sepharose $2 \mathrm{~B}-\mathrm{Cl}$ gel. The elution profile was followed spectrophotometrically at $\lambda 260 \mathrm{~nm}$. Combined fractions from the trailing edge of the included peak which is due to small unilamellar liposomes, were used as a source throughout this study. The SOFICA light scattering photometer (Model 42000) was used to determine the weight average liposomes weight ( $\mathrm{L}_{\mathrm{w}}$ ) of small unilamellar DMPC liposomes. The $\mathrm{Lw}$ was determined in the absence and presence of $\mathrm{CPZ}-\mathrm{HCl}$ both above and below the $\mathrm{CMC}$ over the temperature range of $25^{\circ} \mathrm{C}$ to $40{ }^{\circ} \mathrm{C}$.
\end{abstract}

Results: The Lw was observed to increase linearly in the absence and presence of CPZ-HCl.

The Lw was observed to increase linearly in the absence of CPZ- $\mathrm{HCl}$, from $1.88 \times 10^{6}+0.02 \mathrm{~g} / \mathrm{mol}$ at $25^{\circ} \mathrm{C}$ to $3.25 \times 10^{6}+0.03 \mathrm{~g} / \mathrm{mol}$ at $40{ }^{\circ} \mathrm{C}$. Similarly, the Lw was observed to increase linearly in the present of $\mathrm{CPZ}-\mathrm{HCl}$, for example at $18 \mathrm{mmol}$ drug concentration, the Lw increases from $11 \times 10^{6}+0.04$ $\mathrm{g} / \mathrm{mol}$ at $25^{\circ} \mathrm{C}$ to $13.75 \times 10^{6}+0.03 \mathrm{~g} / \mathrm{mol}$ at $40^{\circ} \mathrm{C}$. When the data are presented as a function of CPZ-HCl concentration, a gradual increase in Lw was observed below the CMC. Little increase in Lw however, was observed at post-micellar concentrations of $14 \mathrm{mmol}$ and $18 \mathrm{mmol}$.

Conclusion: The increase in Lw in the presence of the model cationic, surface-active solute $\mathrm{CPZ}-\mathrm{HCl}$ as a function of concentration and temperature indicate that CPZ-HCl interacts with small unilamellar DMPC liposomes at concentrations below and above the CMC.

Keywords: CPZ-HCl, DMPC liposome, Temperature, CMC

(C) 2019 The Authors. Published by Innovare Academic Sciences Pvt Ltd. This is an open-access article under the CC BY license (http://creativecommons.org/licenses/by/4.0/) DOI: http://dx.doi.org/10.22159/ijap.2019v11i4.32519

\section{INTRODUCTION}

Liposomes have been extensively used as drug delivery systems for a wide range of drugs [1-10]. Liposomes were the first nanoscale drug delivery systems to be approved for clinical use in 1995. Since then, the technology has grown considerably, and pioneering recent work in liposome-based delivery systems has brought about remarkable developments with significant clinical implications [11]. In addition, aqueous liposomal dispersions of phosphatidylcholines have been widely studied as model membranes because of their striking resemblance to biological, as they consist of the lipid bilayer, either multilayer arranged concentrically or single bilayer enclosing a volume of an aqueous medium [12]. The study of the interaction of drugs with the aqueous liposomal dispersions of phospholipids may be useful in elucidating both membrane structure and function and can lead to a better understanding of the interactions of drugs with bio-membranes. The interaction of a range of solutes with liposomes has been previously examined, including proteins [13], cholesterol [14], enzymes [15], estradiol, fluorouracil and antisense oligonucleotide [16] antibiotics [17], cortisone esters [18], nifedipine [19], certain antipsychotics [20] and phenothiazines [21, 22]. The interaction of $\mathrm{CPZ}-\mathrm{HCl}$ with phospholipid liposomes has been reported [23-25]. Using electron spin resonance spectroscopy $\mathrm{CPZ}$ and perphenazine have been shown to be preferentially located in the polar part of the liposomal bilayer, whereas promethazine and the oxidized derivative of CPZ are basically found in the hydrophobic interior of the bilayer [25]. An equilibrium dialysis study with CPZ$\mathrm{HCl}$ showed that the drug has a similar binding affinity for liver microsomes, mitochondrial membrane, myelin vesicles, erythrocyte membranes as well as sonicated egg lecithin liposomes and it was concluded that the major intracellular binders for $\mathrm{CPZ}-\mathrm{HCl}$ are the non-polar moieties of membrane phospholipids and thus hydrophobic interactions are mainly involved [24]. The effect of $\mathrm{CPZ}-\mathrm{HCl}$ on the rat synaptic plasma membranes using nitroxide spin labels revealed that the drug decreases the mobility of the polar head group and it was observed that such action was inhibited by $\mathrm{Ca}$ ions [25]. A previous study has observed that $\mathrm{CPZ}-\mathrm{HCl}$ inhibits the incorporation of orthophosphate and glycerol (precursors in phospholipids biosynthesis) into phosphatidylcholine and phosphatidylethanolamine of krebs asites tumor cells in vitro and it was suggested that $\mathrm{CPZ}-\mathrm{HCl}$ and other cationic amphiphiles could be used as potential tools for modifying phospholipids of tumor cells [26]. $\mathrm{CPZ}-\mathrm{HCl}$ was observed at anesthetic concentrations to protect human erythrocytes against hemolysis, increase the mean cellular volume and decrease the sedimentation rate of the erythrocytes [27]. A study using P-NMR has indicated that $\mathrm{CPZ}-\mathrm{HCl}$ binding to phosphatidylserine in the bilayer enhances phospholipid head group mobility [25].

Small unilamellar liposomes has been used as drug delivery systems in in vivo and in vitro experiments [28]. The use of small unilamellar liposomes as drug delivery systems confer the advantage of selectivity over large unilamellar liposomes for drug delivery to a variety of sites including tumors and lymph nodes [29]. Liposome size may be estimated by a number of techniques, such as light scattering [30], photon correlation spectroscopy [31], membrane osmometry [32] and Transmission electron microscopy [33].

The present study investigates the possible influence of the model, cationic, surface active solute $\mathrm{CPZ}-\mathrm{HCl}$ on the size of small unilamellar DMPC liposomes as a function of temperature and CPZ$\mathrm{HCl}$ concentration (below and above the CMC). The size of DMPC liposomes is measured as the weight average liposome weight (Lw) which is determined using light scattering photometry. Drug encapsulation in a liposomal drug delivery system improves the 
pharmacokinetic and pharmacodynamic properties to such an extent that the drugs can be brought into regular use [34]. This nessestates the importance of applying various formulation techniques and/or formulation additives to optimize the encapsulating efficiency of liposomes.

This study reflects the influence of the model, cationic, surface-active solute $\mathrm{CPZ}-\mathrm{HCl}$ on liposomal size and hence the possible use of other similar surfactants as formulation additives to optimize the encapsulating efficiency of liposomes as drug delivery systems.

\section{MATERIALS AND METHODS}

Synthetic dimyristoyl phosphatidylcholine (DMPC) (not less than 98\% pure), chlorpromazine hydrochloride ( $\mathrm{CPZ}-\mathrm{HCl}$ ) and bovine plasma albumin were purchased from Sigma Co. $\mathrm{KCl}$, chloroform and tetrahydrofuran (THF) were purchased from BDH and were all of Analar grade. Diphenylhexatriene (DPH) was purchased from Aldrich Co. Sepharose 2B-Cl was purchased from Pharmacia Co.

\section{Preparation of small unilamellar DMPC liposomes}

Accurately weighed DMPC was dissolved in chloroform $(10 \mathrm{mg} / \mathrm{ml})$ in $50 \mathrm{ml}$ quick-fit round bottom flask. The organic solvent was evaporated on a rotary vacuum evaporator (Rotavapor R100, Buchi, Switzerland) at $40{ }^{\circ} \mathrm{C}$. Any remaining chloroform was removed by applying a jet of dry nitrogen. The required amount of $0.1 \mathrm{M} \mathrm{KCl}$ solution was added, the $\mathrm{pH}$ was then adjusted to 6.2 using $0.1 \mathrm{M} \mathrm{NaOH}$ or $\mathrm{HCl}$ acid and the flask was then swirled using a vortex mixer to form multilayer DMPC liposomes at $40^{\circ} \mathrm{C}$. Multilayer DMPC liposomes were sonicated using a Dawe Soniprobe Sonicator (Lucas instrument, UK), at $100 \mathrm{~W}$ under nitrogen for $30 \mathrm{~min}$. The sample was kept in ice during sonication to avoid overheating. The sonicated liposomes were fractionated on a $40 \times 2.5 \mathrm{~cm}$ column of Sepharose $2 \mathrm{~B}-\mathrm{Cl}$ which was previously washed several times with $0.1 \mathrm{M} \mathrm{KCl}$ (pH 6.2). $0.5 \mathrm{ml}$ of 16 mmol sonicated liposomes was applied to the column. Fractions of $\simeq$ $1.0 \mathrm{ml}$ were collected over a period of $4 \mathrm{hr}$. the elution profile as followed spectrophotometrically at $\lambda 260 \mathrm{~nm}$ using (CE 5095, Double Beam Spectrophotometer, Cecil Co., Cambridge), exhibited an excluded peak (A) due to large multilamellar liposomes and an included peak (B, C1,C2 and C3) (fig. 1) due to small unilamellar liposomes. These fractions (i.e. A, B and C1,C2 and C3) exhibited different specific refractive index increment ( $\mathrm{dn} / \mathrm{dc}$ ) values (fig. 2) which indicates variations in structure and size of the liposomes. Combined fractions from the trailing edge of the included peak (i.e. C1,C2 and C3) (fig. 2) which is due to small unilamellar liposomes[35] were used as a source throughout this light scattering study, as no difference in liposomal size could be detected for individual fractions (C1,C2 and C3) as revealed by plotting the scattered intensity at $90^{\circ}\left(\mathrm{S}_{90}\right)$ as a function of lipid concentration (fig. 4) using the SOFICA light scattering photometer (Model 42000).

\section{Determination of small unilamellar DMPC liposomes concentration}

Small unilamellar DMPC liposomes concentration was determined spectrofluorimetrically by the method of London and Feigenson [36]. The protocol for the assay was as follows:

(i) $2 \mu \mathrm{l}$ of $3 \mathrm{mmol} \mathrm{DPH}$ in THF was added to a solution of $3 \mathrm{ml}$ of 0.1 $\mathrm{M} \mathrm{KCl}(\mathrm{pH} \mathrm{6.2)}$ and $50 \mu \mathrm{l}$ of the DMPC liposome dispersion.

(ii) Tubes were incubated in the dark for $45 \mathrm{~min}$ at $40{ }^{\circ} \mathrm{C}$ in a water bath and the fluorescent intensity was measured at $25{ }^{\circ} \mathrm{C}$ using a Perkin-Elmer spectrofluorimeter (Model 1000) with a temperature controller cell holder, connected to a Grant-thermo-circulator. The instrument was calibrated using quinine sulphate in $0.1 \mathrm{M} \mathrm{HCl}$ as a fluorescence standard. The excitation wavelength was $365 \mathrm{~nm}$ and the emission wavelength was $460 \mathrm{~nm}$. A calibration curve of DMPC liposomes concentration against fluorescent intensity was constructed and was employed in the conversion of fluorescent intensities values to concentrations.

\section{Stability assessment of small unilamellar DMPC liposomes}

Small unilamellar phospholipid liposomes may exhibit size transformation to larger multilayer liposomes via liposome fusion or lipid exchange, most readily near phase transition temperature (Tc) because of the strain induced in the membrane by the small radius of curvature of the Liposomes [37]. The stability of the small unilamellar DMPC liposomes was assessed for $14 \mathrm{~d}$ during which time the liposomes were kept in an incubator at $25^{\circ} \mathrm{C}$.

\section{Determination of the critical micelle concentration (CMC) of CPZ-HCl}

The $\mathrm{CMC}$ of $\mathrm{CPZ}-\mathrm{HCl}$ in $0.1 \mathrm{M} \mathrm{KCl}(\mathrm{pH} 6.2)$ was determined by the Wilhelmy plate method [38] and a DMA digital density meter that comprised a DMA 60 measuring unit combined with a DMA 602 remote cell (Anton Pear-Austria). The temperature of the external cell was controlled by circulating water from a Grant-thermocirculator connected to a viscometry water bath (Townson and Mercer). The Wilhelmy plate was calibrated by determining the surface tension of carbon tetrachloride (Analar grade) at $25{ }^{\circ} \mathrm{C}$. A surface tension value of $26.01+0.05 \mathrm{mNm}^{-1}$ compared with a literature value of $26.15 \mathrm{mNm}^{-1}$ [39] was obtained. The DMA density meter was calibrated by determining the density of carbon tetrachloride (Analar grade) at $20^{\circ} \mathrm{C}$. A value of $1.5937+0.004 \mathrm{~g} / \mathrm{ml}$ was obtained compared with a literature value of $1.5940 \mathrm{~g} / \mathrm{ml}$ [40] The CMC of CPZ-HCl in $0.1 \mathrm{M} \mathrm{KCl}(\mathrm{pH} \mathrm{6.2)}$ was found to be $12.8+0.05$ mmol at $25^{\circ} \mathrm{C}$ by the Wilhelmy plate method which is in agreement with the value of $13.0+0.05 \mathrm{mmol}$ obtained using densitometry.

\section{Preparation of DMPC liposome-CPZ-HCl dispersions for light scattering measurements}

Accurately weighed CPZ-HCl was added as a powder to aliquots of the combined fractions of small unilamellar DMPC liposomes to provide concentrations both above and below the CMC. Serial dilutions of these initial concentrations were made. The samples were then equilibrated for $72 \mathrm{~h}$ protected from light in a water bath at $25{ }^{\circ} \mathrm{C}$. The $\mathrm{L}_{w}$ was determined over the temperature range of 25 ${ }^{\circ} \mathrm{C}$ to $40{ }^{\circ} \mathrm{C}$. All the $\mathrm{L}_{\mathrm{w}}$ determinations were made above the $\mathrm{T}_{\mathrm{c}}$ of DMPC of $23{ }^{\circ} \mathrm{C}$, as it was observed that saturated phospholipid liposomes undergo fusion and size transformation to larger liposomes as the incubation temperature is decreased below $\mathrm{T}_{\mathrm{c}}$ [39].

The dispersions were then prepared for light scattering measurements by filtration through a $0.45 \mu \mathrm{m}$ pore size Millipore filter into an aqueous light scattering cell. This operation was performed in a laminar flow cabinet fed with pre-filtered compressed air. The light scattering cell was cleaned in chromic acid and rinsed with fresh filtered distilled water. The cleaning procedure is completed by using acetone vapor followed by rinses with fresh filtered distilled water

Determination of the weight average liposomal weight $\left(L_{w}\right)$ using the SOFICA Light scattering photometer

The SOFICA light scattering photometer (Model 42000) was used to determine the $\mathrm{L}_{\mathrm{w}}$. The temperature of the instrument is controlled by an electrical thermo-regulator. An external Grant-thermo-circulator was fitted to the instrument to achieve $\pm 0.05^{\circ} \mathrm{C}$ temperature control.

The $\mathrm{L}_{w}$ was determined using the following equation:

$$
\mathrm{KC} / \mathrm{R} 90=1 / \mathrm{Lw}+2 \mathrm{~A}_{2} \mathrm{C} \ldots . . .(1)
$$

$\mathrm{K}=$ The optical constant of DMPC liposome dispersion.

$\mathrm{C}=$ Concentration of DMPC liposome dispersion.

R $90=$ Rayleigh ratio $=I_{90} / I_{0}=$ the ratio of the intensity of the scattered light at $90^{\circ}$ to the intensity of the incident light.

$\mathrm{L}_{\mathrm{w}}=$ The weight average liposomes weight of DMPC.

$2 \mathrm{~A}_{2}=$ The second virial coefficient.

$\mathrm{K}$ is given by the following equation:

$$
\mathrm{K}=\frac{2 \pi^{2} \mathrm{n}^{2}(\mathrm{dn} / \mathrm{dc})^{2}}{\lambda^{4} \mathrm{NA}}
$$

no $=$ Refractive index of the solvent.

$\mathrm{dn} / \mathrm{dc}=$ Specific refractive index increment of DMPC liposome dispersion.

$\lambda^{4}=$ Wavelength in $\mathrm{cm}$.

$\mathrm{NA}=$ Avogadro's number $=6.02 \times 10$ [23] . 
A plot of KC/R 90 against $C$ will yield a straight line, the reciprocal of the intercept gives the Lw and the slope gives the second virial coefficient (A2) which gives information about solvent-solute interaction.

Anisotropic particle exhibits additional scattering due to change in orientation and there is some horizontally polarized scatter light. It was shown that the observed R90 must be multiplied by a depolarization factor known as the Cabannes factor [40], which is given as:

Cabannes' factor $=6-7 d / 6+6 d$

Where $\mathrm{d}$ (depolarization at $90^{\circ}$ ) is the ratio of the intensity of horizontally polarized scatter light to the intensity of the vertically polarized component.

The SOFICA was calibrated using spectroscopic grade toluene and standard block of perspex $\mathrm{At}=90 \quad{ }^{\circ}$ and $23^{\circ} \mathrm{C}$. The calibration constant $(\mathrm{C})$ is given by:
$\mathrm{R} 90=\mathrm{C} \mathrm{S}_{90}$

Where $\mathrm{R} 90=$ Rayleigh ratio of toluene at $23{ }^{\circ} \mathrm{C}$ obtained from reference [41].

$S_{90}=$ the ratio of the scattered intensity of toluene at $90^{\circ}$ to the scattered intensity of standard block of perspex at $90^{\circ}$ measured using The SOFICA light scattering photometer.

The calibration constant was $5.75 \times 10^{-5}$ and was checked by determining the weight average molecular weight of Bovine Plasma Albumin according to equation (1) by plotting KC/R90 against different concentrations and the reciprocal of the intercept gives the weight average molecular weight, after correction for the Cabannes' factor according to equation (3). A value of $67.72 \times 10^{3}+0.05$ was obtained compared with $66.16 \times 10^{3}$ [42]

The $\mathrm{L}_{\mathrm{w}}$ were determined using this procedure; for example, see (fig 1).

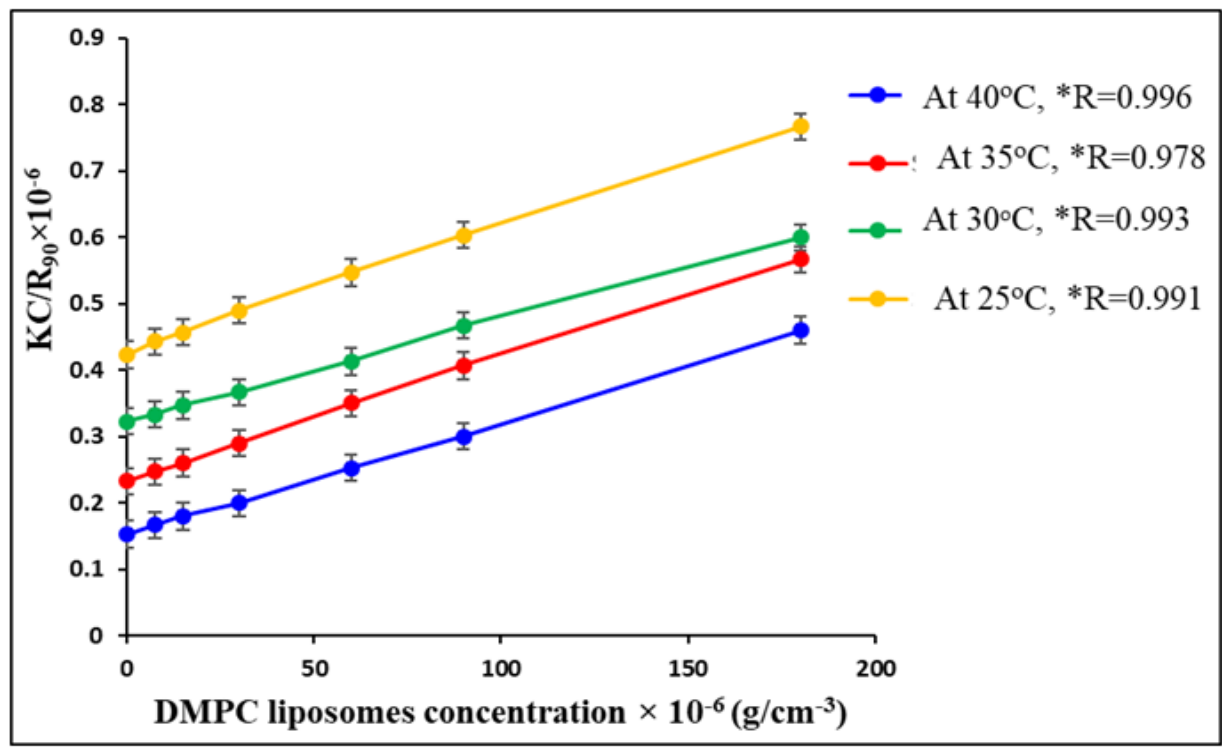

Fig. 1: Determination of the weight average small unilamellar DMPC liposomes weight (Lw) at $\lambda 546$ and at different temperatures (the reciprocal of the intercept was taken as $L w$ after correction for the Cabannes' factor). ${ }^{*} R=$ the regression line correlation coefficient. The values obtained were the mean of three experiments $(n=3)$. The standard deviations are shown as error bars and all values were in the range of $+0.01-0.03$

Determination of the specific refractive index increment (SRII) of DMPC liposome dispersion

The specific refractive index increment-SRII-(dn/dc) which is one of the components of the optical constant $(\mathrm{K})$ in equation (2) was determined using a differential refractometer (Polymer Consultant Ltd). The displacement of the light beam emerging from the refractometer by the dispersion is measured using a micrometer eyepiece. The displacement value $(\Delta d)$ is determined by measuring the position of the slit image $\left(d_{l}\right)$. The cell is then rotated through $180^{\circ}$ and the position measured again $\left(d_{2}\right)$. The difference between these two reading minuses $\Delta d$ o for the solvent will yield $\Delta \mathrm{d}$ which is related to the refractive index difference between the dispersion and the solvent ( $\Delta \mathrm{n}$ ) by the following equation

$$
\Delta \mathrm{n}=\mathrm{K} \Delta \mathrm{d} \ldots \ldots . .(4)
$$

Where $\mathrm{K}$ is the calibration constant of the instrument determined by using the refractometric calibration data of a series of standard solutions of Analar grade $\mathrm{KCl}$ with known values [43]. The calibration constant $(\mathrm{K})$ was obtained from equation (4) by determining $\Delta \mathrm{d}$ experimentally, for which a value of $9.14 \times 10^{-4}+0.05$ as a mean of six concentrations was obtained.

SRII $(\mathrm{dn} / \mathrm{dc})$ is obtained from the gradient of the graph of $\Delta \mathrm{n}$ against different concentrations. For example, see (fig. 2). The calibration was checked by determining $\mathrm{dn} / \mathrm{dc}$ for Bovine Plasma Albumin at 23 ${ }^{\circ} \mathrm{C}$, when a value of $0.184+0.005 \mathrm{~cm} / \mathrm{g}$ was obtained compared with $0.186 \mathrm{~cm} / \mathrm{g}$ [42].

Determination of the refractive index of the solvent $\left(n_{0}\right)$

The refractive index of the solvent $\left(\mathrm{n}_{0}\right)$ is another component of the optical constant (K) in equation (2). Measurements were carried out using the Abbe refractometer [44], temperature regulated by a Grant-thermoregulator. The instrument was calibrated using distilled water.

\section{RESULTS AND DISCUSSION}

Gel fractionation elution profile of the sonicated DMPC liposomes exhibited an excluded peak (A), a front edge of the included peak (B) as well as the trailing edge of the included peak (C1, C2, and C3) (fig. 2)

Different fractions from the elution profile of the sonicated DMPC liposomes exhibited different SRII $(\mathrm{dn} / \mathrm{dc})$ values, for the excluded peak (A), the front edge of the included peak (B) as well as the trailing edge of the included peak (C1, C2 and C3) (fig. 3). This indicates different liposome size and structure for these fractions. 


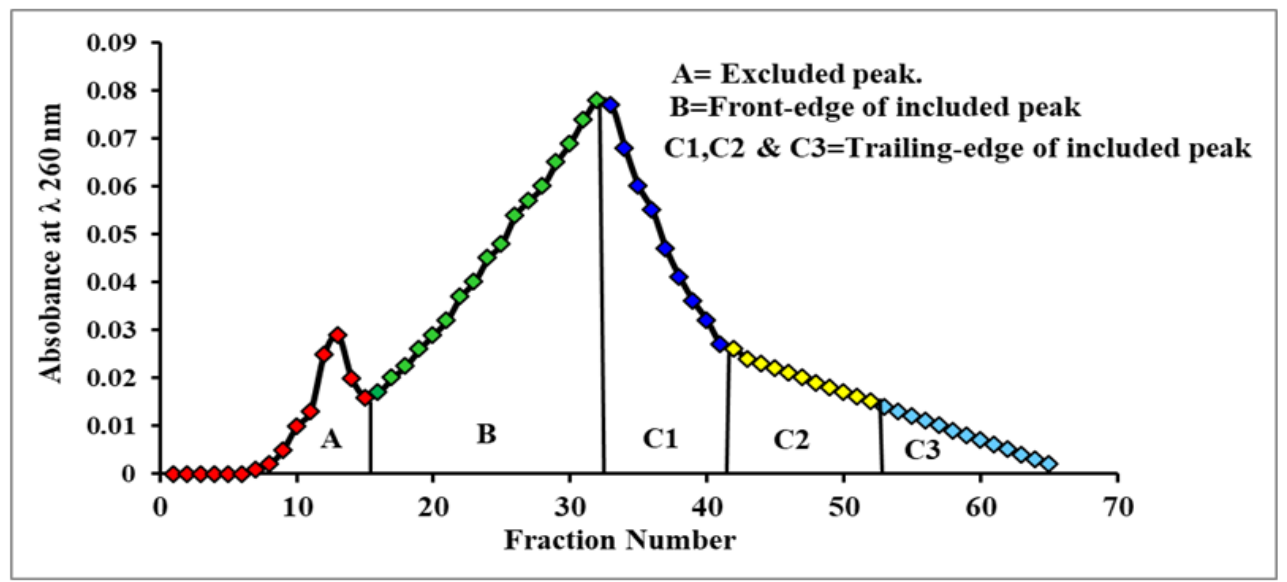

Fig. 2: Gel fractionation elution profile of sonicated DMPC liposomes at $\lambda 260 \mathrm{~nm}$ using Sepharose 2B-Cl

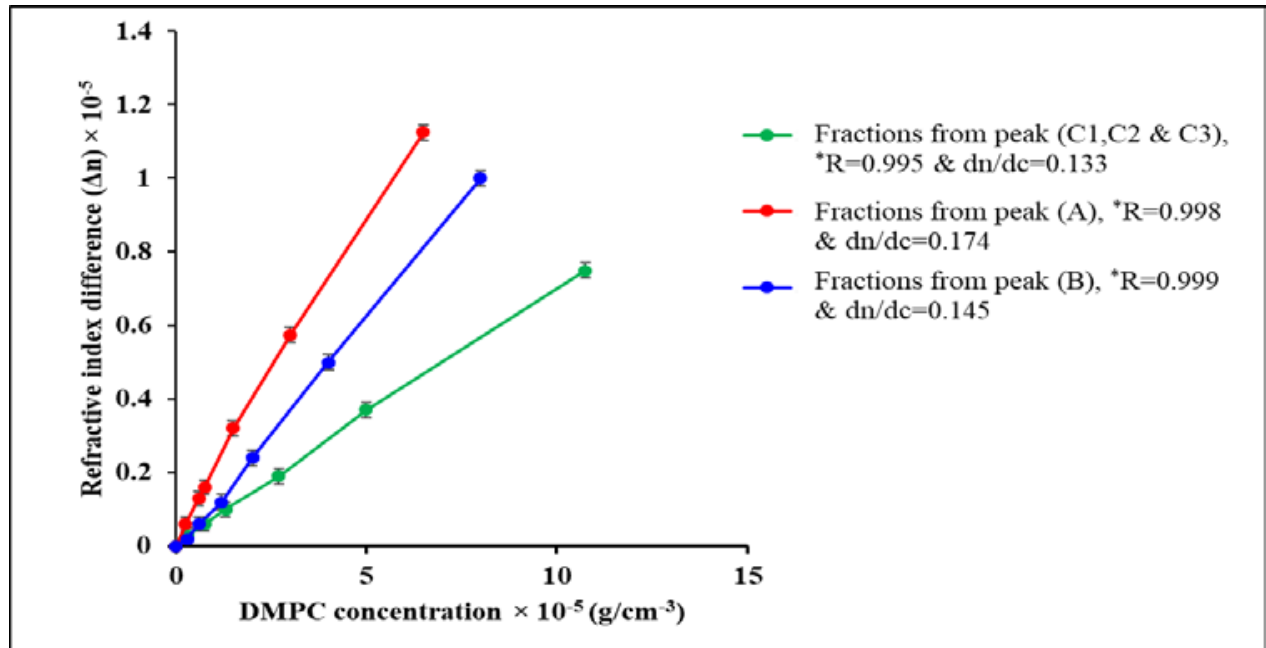

Fig. 3: Determination of the refractive index increment (dn/dc) of different fractions of sonicated DMPC liposomes from peak (A), peak (B) and peak $\left(\mathrm{C1}, \mathrm{C2}\right.$ andC3). ${ }^{*} \mathrm{R}=$ the regression line correlation coefficient. The values obtained were the mean of three experiments $(\mathrm{n}=$ 3 ). The standard deviations are shown as error bars and all values were in the range of $+0.02-0.04$

Fractions from the trailing edge of the included peak (C1, C2 and C3) however, showed no differences in liposome size as no variations in the scattered intensity at $90^{\circ}\left(\mathrm{S}_{90}\right)$ as a function of concentration could be detected (fig. 4).

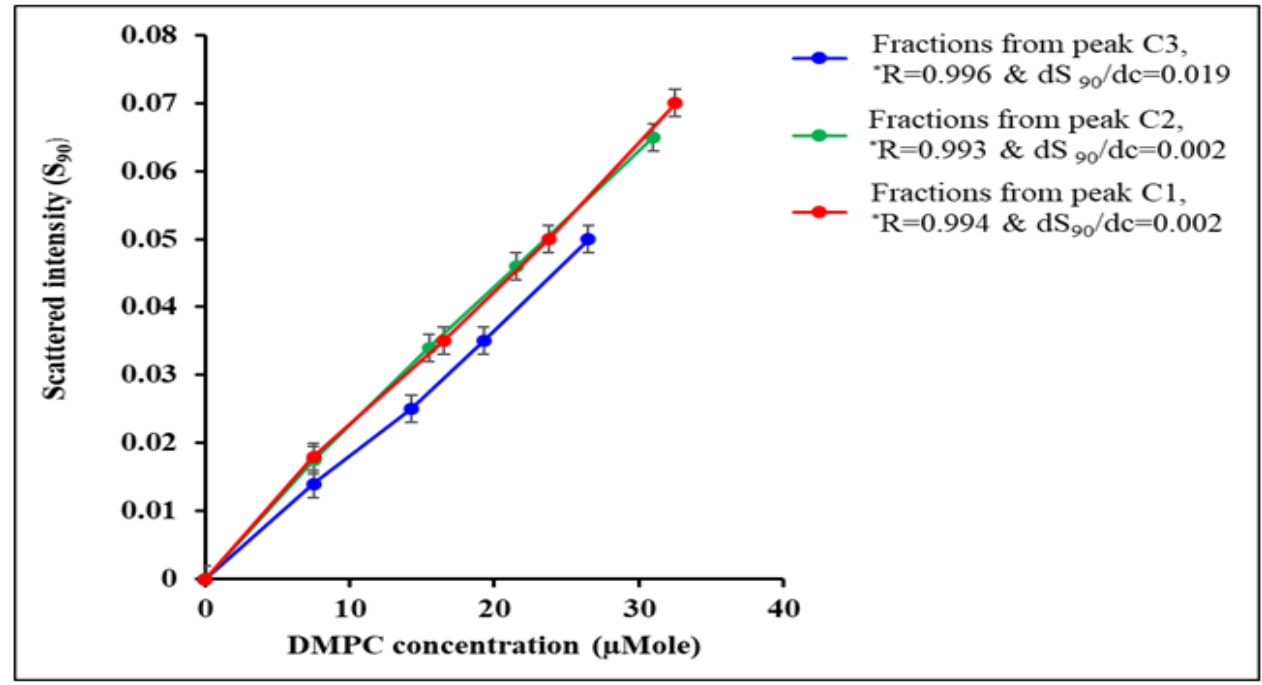

Fig. 4: Changes in the scattered intensity $\left(S_{90}\right)$ of different fractions from the trailing edge of the included peak $(C 1, C 2$ and $C 3)$ against DMPC concentration at $25^{\circ} \mathrm{C}$. ${ }^{*} \mathrm{R}=$ the regression line correlation coefficient. The values obtained were the mean of three experiments ( $\mathrm{n}=$ $3)$. The standard deviations are shown as error bars and all values were in the range of $+0.005-0.02$ 


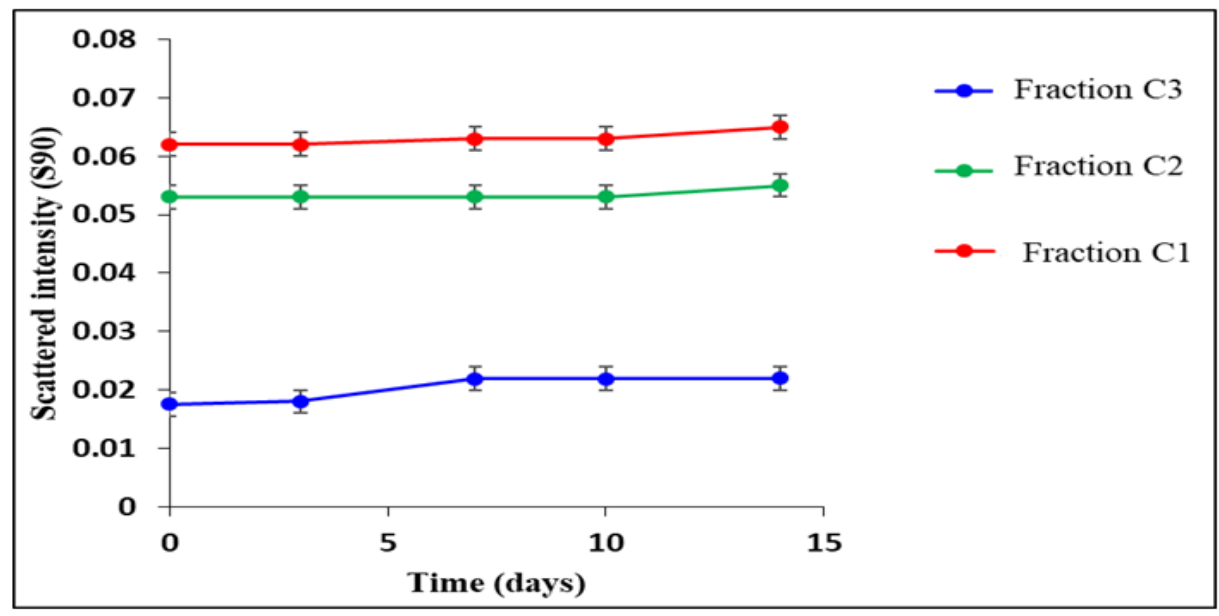

Fig. 5: Changes in the scattered intensity $\left(S_{9_{0}}\right)$ of different fractions of small unilamellar DMPC liposomes from the trailing edge of the included peak ( $\mathrm{C} 1, \mathrm{C} 2$ and $\mathrm{C} 3)$ against time at $25^{\circ} \mathrm{C}$. The values obtained were the mean of three experiments $(\mathrm{n}=3)$. The standard deviations are shown as error bars and all values were in the range of $+0.005-0.02$

The stability of small unilamellar (DMPC) liposomes was assessed over a period of $14 \mathrm{~d}$, when a slight increase in the scattered intensity at $90^{\circ}\left(\mathrm{S}_{90}\right)$ occurred (fig. 5$)$.

Since small unilamellar phospholipid liposomes are unstable because of the strain induced in the membrane by the small radius of curvature of the liposomes, they undergo size transformation to larger liposomes through fusion and/or lipid exchange mechanism most readily near $\mathrm{T}_{\mathrm{c} .}[35]$

The stability of small unilamellar (DMPC) liposomes was assessed over a period of $14 \mathrm{~d}$, when a slight increase in the scattered intensity at $90^{\circ}\left(\mathrm{S}_{90}\right)$ occurred (fig. 5), suggesting only a small degree of liposome fusion. This relatively long term stability might be due to the adsorption of negatively charged $\mathrm{Cl}$-ions as revealed by electrophoretic mobility measurement of DMPC liposomes [45]. The adsorption of these negatively charged Clions by liposomes may create electrostatic repulsive forces that prevent liposome aggregation and hence reduce liposome fusion and/or lipid exchange [45]. The $\mathrm{L}_{\mathrm{w}}$ was observed to increase linearly from $1.88 \times 10^{6}+0.02 \mathrm{~g} / \mathrm{mol}$ at $25^{\circ} \mathrm{C}$ to $3.25 \times 10^{6}+0.03$ $\mathrm{g} / \mathrm{mol}$ at $40{ }^{\circ} \mathrm{C}$ in the absence of $\mathrm{CPZ}$. $\mathrm{HCl}$ (fig. 6). This increase in the liposomal weight with temperature may reflect an increase in the volume of the aqueous interior of the liposomes together with an increase in the bilayer thickness resulting from increased fluidity of the phospholipid acyl chains. It was observed that small unilamellar DMPC liposomes undergo large changes in dimensions and hydration as a function of temperature; where the liposome internal volume increases near six times ongoing from $15{ }^{\circ} \mathrm{C}$ to $30^{\circ} \mathrm{C}$ and the bound water increases more than six times. [46] Other studies have revealed that $\mathrm{CPZ}-\mathrm{HCl}$ at a concentration of $10^{-4} \mathrm{M}$, increases the mean cellular volume of erythrocytes and the membrane area was found to expand by $2.7 \%$. At higher concentrations, the membrane area was found to expand by $5 \%$ [50]. $\mathrm{L}_{\mathrm{w}}$ was also observed to increase linearly as a function of temperature in the presence of $\mathrm{CPZ}-\mathrm{HCl}$ both below and above the CMC (fig. 6).

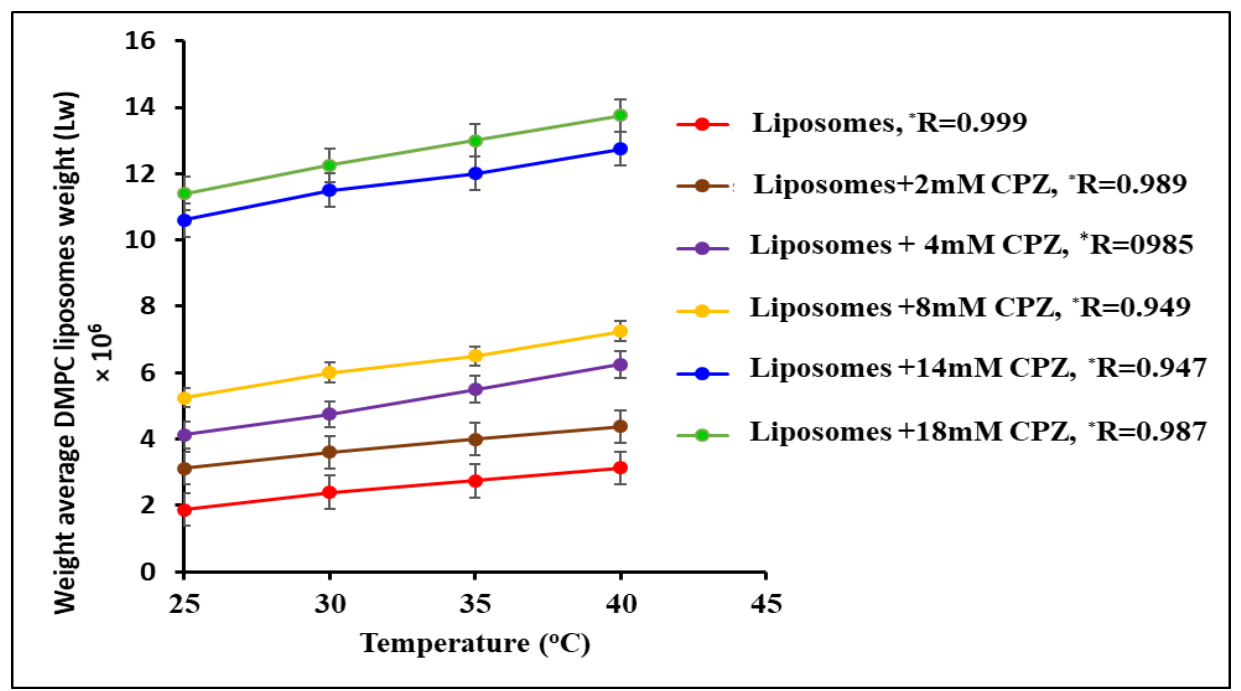

Fig. 6: Temperature-dependent weight average DMPC liposomes weight (Lw) with different CPZ concentration below and above the CMC. ${ }^{*} R=$ the regression line correlation coefficient. The values obtained were the mean of three experiments $(n=3)$. The standard deviations are shown as error bars and all values were in the range of $+0.02-0.05$

When the data are presented as a function of CPZ-HCl concentration (fig. 7) a gradual increase in $L_{w}$ was observed below the CMC. Little increase in $L_{w}$ however, was observed at post-micellar concentrations of $14 \mathrm{mmol}$ and $18 \mathrm{mmol}$. As only
R90 values were available for $L_{w}$ determinations, the data for these high $\mathrm{CPZ}-\mathrm{HCl}$ concentrations may be considered as approximations because the liposome dimension is closed to $\lambda / 20$ limit. 


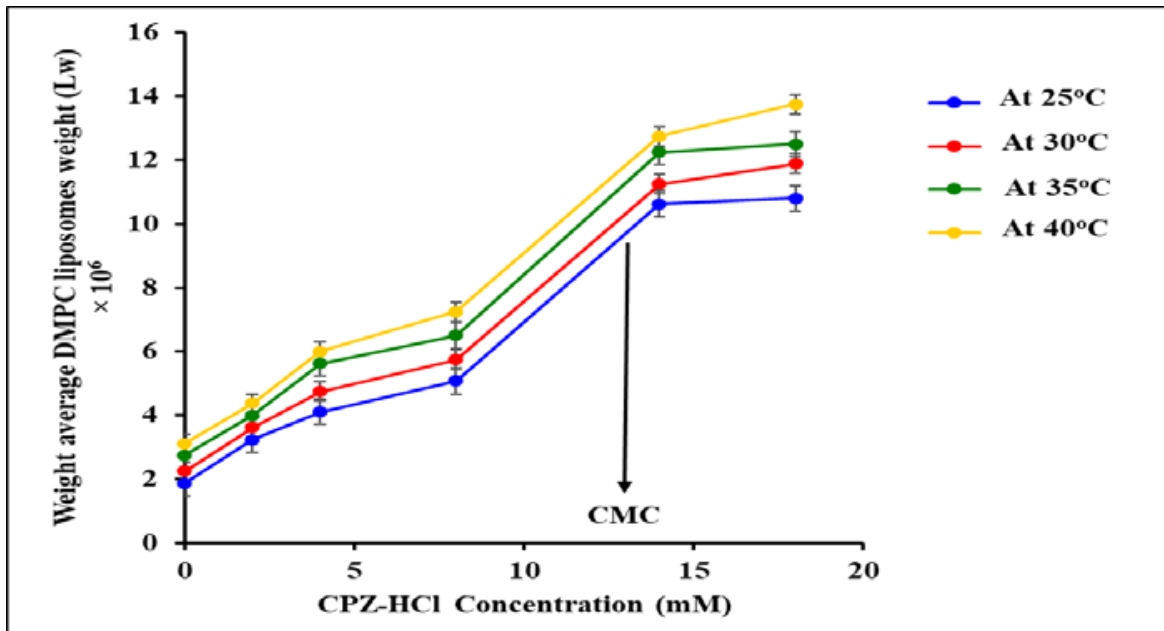

Fig. 7: Weight average DMPC liposomes weight as a function of $\mathrm{CPZ}-\mathrm{HCl}$ concentration at different temperatures. The values obtained were the mean of three experiments $(n=3)$. The standard deviations are shown as error bars and all values were in the range of $+0.02-0.05$

The increase in $\mathrm{L}_{w}$ in the presence of $\mathrm{CPZ}-\mathrm{HCl}$ may be explained on the basis that the negatively charged liposomes resulting from $\mathrm{Cl}^{-}$ adsorption will facilitate the buildup of the positively charged CPZ ions. Such buildup of CPZ ions might increase the phospholipid acyl chain fluidity resulting in a further increase in the liposome volume and the bilayer thickness.

At the experimental $\mathrm{pH}$ of $6.2, \mathrm{CPZ}$ will be mostly ionized as it has a pka of 9.2. [47] CPZ was observed to shift the negative electrophoretic mobility of DMPC liposomes in $0.1 \mathrm{M} \mathrm{KCl} \mathrm{(pH} \mathrm{6.2)} \mathrm{to}$ positive mobility [44]. A similar buildup of positively charged CPZ ions was also observed in negatively charged DMPC liposomes containing dicetyl phosphate [48]. Also, it has been observed that $\mathrm{CPZ}$ increases diplmotylphosphatidyl choline fluidity in the presence of negatively charged myristic acid [49]. This buildup of CPZ ions might increase the phospholipid acyl chain fluidity resulting in a further increase in the liposome volume and the bilayer thickness. In addition, it was observed that the interaction of CPZ with DMPC liposomes had inherent effects on the $\mathrm{T}_{\mathrm{c}}$ and hence, fluidity of DMPC phospholipid membranes. It was shown that $\mathrm{CPZ}$ intercalates within the membrane bilayers to form a drug/phospholipid complex [50].

\section{CONCLUSION}

The model cationic surface active drug, $\mathrm{CPZ}$. $\mathrm{HCl}$ was observed to interact with small unilamellar DMPC liposomes at concentrations below and above the CMC. $\mathrm{L}_{w}$ was observed to increase linearly as a function of temperature both in the presence and absence of $\mathrm{CPZ}-\mathrm{HCl}$. When the data are presented as a function of $\mathrm{CPZ}-\mathrm{HCl}$ concentration, a gradual increase in $\mathrm{L}_{\mathrm{w}}$ was observed below the CMC, whereas little increase in $\mathrm{L}_{\mathrm{w}}$, was observed at post-micellar concentrations. The observed increase of $\mathrm{L}_{\mathrm{w}}$ upon the partitioning of $\mathrm{CPZ}-\mathrm{HCl}$ into the bilayer may reflect an increase in the volume of the aqueous interior of the liposome together with an increase in the bilayer thickness resulting from greater fluidity of the phospholipid acyl chain.

\section{ACKNOWLEDGMENT}

The author is grateful to the college of pharmacy and health sciences, Ajman University for their provision of the research facilities.

\section{AUTHORS CONTRIBUTIONS}

All the author have contributed equally

\section{CONFLICT OF INTERESTS}

Declared none

\section{REFERENCES}

1. Akbarzadeh A, Rezaei Sadabady R, Davaran S, Joo SW, Zarghami $\mathrm{N}$, Hanifehpour Y, et al. Liposome: classification, preparation, and applications. Nanoscale Res Lett 2013;8:102-11.
2. Gabizon A. Drug carrier systems. In: Roerdink FHD, Kron AM. editors. Liposomes as a drug delivery system in cancer therapy. First ed. Chichester: Wiley; 1989. p. 185-211.

3. A Storm G, Roerdink FH, Steerenberg PA, de Jong WH, Crommelin DJA. Influence of lipid composition on the antitumor activity exerted by doxorubicin-containing liposomes in a rat solid tumor model. Cancer Res 1987;47:3366-72.

4. Wiebe VJ, Degregorio MW. Liposome-encapsulated amphotericin-B: A promising new treatment for disseminated fungal infections. Rev Infect Dis 1988;19:1097-101.

5. Vogel NJ, Vogel CL, Henderson IC. The role of liposomal anthracyclines and other systemic therapies in the management of advanced breast cancer. Semin Oncol 2004;31;106-46.

6. Malam Y, Loizidou M, Seifalian AM. Liposomes and nanoparticles: nanosized vehicles for drug delivery in cancer. Trends Pharmacol Sci 2000;30:592-9.

7. Schurmann D, Dormann A, Grunewald T, Ruf B. Successful treatment of AIDS-related pulmonary Kaposi's sarcoma with liposomal daunorubicin. Eur Respir J 1994;7:824-5.

8. Sarvesh Sharma, Vimal Kumar. In vitro cytotoxicity effect on mcf-7cell line of co-encapsulated artesunate and curcumin liposome. Int J Pharm Pharm Sci 2016;8:286-92.

9. Razan Solayman Awad, Wassim Abdel Wahed, Yaser Bitar. Evaluating the impact of preparation conditions and formulation on the accelerated stability of tretinoin loaded liposomes prepared by the heating method. Int J Pharm Pharm Sci 2015;7:171-8.

10. Smita Bonde, Sukanya Nair. Advances in liposomal drug delivery system: Fascinating types and potential applications. Int J Appl Pharm 2017; 9:1-7.

11. Claudia Zylberberg, Sandro Matosevic. Pharmaceutical liposomal drug delivery: a review of new delivery systems and a look at the regulatory landscape. Drug Delivery 2016;23:3319-29.

12. Giuseppina Bozzuto, Agnese Molinari. Liposomes as nanomedical devices. Int J Nanomed 2015;10:975-99.

13. Kuan Yi Lu, Sheng Ce Tao, Tzu Ching Yang,Yu Hsuan Ho, Chia Hsien Lee, Chen Ching Lin, et al. Profiling lipid-protein interactions using nonquenched fluorescent liposomal nanovesicles and proteome microarrays. Mol Cell Proteomics 2012;11:1177-90.

14. Antoaneta V Popova, Dirk K Hincha. Effects of cholesterol on dry bilayers: interactions between phosphatidylcholine unsaturation and glycolipid or free sugar. Biophys J 2007;93:1204-14.

15. Valeriya M Trusova, Galyna P Gorbenko, Julian G Molotkovsky, Paavo KJ Kinnunen. Cytochrome c-lipid interactions: new insights from resonance energy transfer. Biophys J 2010;99:1754-63. 
16. El Maghraby GM, Williams AC, Barry BW. Drug interaction and location in liposomes: correlation with polar surface areas. Int ] Pharm 2005;292:179-85.

17. Misagh Alipour, Zacharias E Suntres, Majed Halwani, Ali O Azghani, Abdelwahab Omri. Activity and interactions of liposomal antibiotics in presence of polyanions and sputum of patients with cystic fibrosis. PLoS One 2009;4:e5724.

18. Arrowsmith M, Hadgraft J, Kellaway IW. The interaction of cortisone esters with liposomes as studied by differential scanning calorimetry. Int J Pharm 1983;16:305-18.

19. Hiroko Osanai, Tastuya Ikehara, Seiji Miyauchi, Kazumi Shimono, Jun Tamogami, Toshifumi Nara, et al. A study of the interaction of drugs with liposomes with isothermal titration calorimetry. J Biophysical Chem 2013;4:11-21.

20. Isabel D Alves, Galya Staneva, Cedric Tessier, Gilmar F Salgadod, Philippe Nuss. The interaction of antipsychotic drugs with lipids and subsequent lipid reorganization investigated using biophysical methods. Biochim Biophys Acta 2011;1808:2009-18.

21. Ahmed M, Hadgraft J, Burton JS, Kellaway IW. The interaction of mequitazine with phospholipid model membranes. Chem Phys Lipid 1980;27:251-62.

22. Anteneodo C, Bisch PM, Marques JF. Interaction of chlorpromazine with phospholipid membranes: an EPR study of membrane surface potential effects. Eur Biophys J 1995;23:447-52.

23. Willy Nerdal, Stig Are Gundersen, Vidar Thorsen, Harald Høiland, Holm Holmsen. Chlorpromazine interaction with glycerophospholipid liposomes studied by magic angle spinning solid state 13C-NMR and differential scanning calorimetry. Biochim Biophys Acta Biomembr 2000;1464:16575.

24. Breton J, Viret J, Leterrier F. Calcium and chlorpromazine interactions in rat synaptic plasma membranes: A spin-label and fluorescence probe study. Arch Biochim Biophys 1977;179:625-33

25. Song Chen, Anja Underhaug Gjerde, Holm Holmsen, Willy Nerdal. Importance of polyunsaturated acyl chains in chlorpromazine interaction with phosphatidylserines: a $13 \mathrm{C}$ and 31P solid-state NMR study. Biophysical Chem 2005;117:101-9.

26. Plantavid M, Chap H, Lloveras J, Douste Blazy L. Cationic amphiphilic drugs as potential tools for modifying phospholipid of tumor cells: an in vitro study of chlorpromazine effects on krebs II ascites cells. Biochem Pharmac 1981;30:293-7.

27. Seeman F, Kwant WO, Sauks T, Argent W. Membrane expansion of erythrocyte ghosts by tranquilizers and anesthetics. Biochem Biophys Acta 1969;183:499-511.

28. Szoka FJ, Papahadjopoulos D. Comparative properties and methods of preparation of lipid vesicles (liposomes). Ann Rev Biophys Bioeng 1980;9:467-508.

29. Richardson VJ, Jeyasingh K, Jewkes RF, Ryman BE, Tattersall MHN. Possible tumor localization of Tc-99-m-labeled liposomes: effects of lipid composition, charge and liposome size. J Nucl Med 1978;19:1049-54.
30. Libusa Sikurova, M Kristekova. Fluorescence anisotropy and light-scattering studies of the interaction of insulin with liposomes. J Fluorescence 1993;3:215-7.

31. Duke RW, Dupre DB. Inelastic light scattering at the second critical micellar formation of lecithin. Chem Phys Lett 1976;44:309-12.

32. Kellaway IW, Saunders L. Osmotic pressure studies of some phospholipid sols. Chem Phys Lipid 1970;4:261-8.

33. Baxa U. Imaging of liposomes by transmission electron microscopy. Methods Mol Biol 2018;1682:73-88.

34. Del Amo EM, Rimpelä AK, Heikkinen E, Kari OK, Ramsay E, Lajunen $\mathrm{T}$, et al. Pharmacokinetic aspects of retinal drug delivery. Prog Retin Eye Res 2017;57:134-85.

35. Mason JT, Huang C. Hydrodynamic analysis of egg phosphatidylcholine vesicles. Ann N Y Acad Sci 1978;308:2949.

36. London E, Feigenson GW. A convenient and sensitive fluorescence assay for phospholipid vesicles using diphenylhexatriene. Anal Biochem 1978;88:203-11.

37. Larrabee AL. Time dependent changes in the size distribution of distearoylphosphatidylcholine vesicles. Biochemistry 1979;18:3321-6.

38. Padday JE, Russel DR. The measurement of the surface tension of pure liquids and solutions. J Colloid Sci 1960;15:503-11.

39. Riddick JA, Bunger WB. Organic solvents; techniques of chemistry. Vol. II. 3rd ed. New York: Wiley interscience; 1970.

40. Zimm BH. The scattering of light and the radial distribution function of high polymer solutions. J Chem Phys 1984;16:1093-100.

41. Beattie WH, Booth C. Table of dis-symmetries and correction factors for use in light scattering. J Phys Chem 1964;64:696-7.

42. Pugh WJ, Saunders L. A laser light scattering apparatus. J Pharm Pharmacol 1971;23 Suppl 1:85-8.

43. Huglin MB. Light scattering from polymer solutions. 3rd ed. New York: Academic Press; 1972

44. Beckett AH, Stenlake JB. Practical pharmaceutical chemistry. Part 2. 3rd ed. The Athlone Press of the University of London; 1976.

45. Farah FH. Micro-electrophoretic mobility study of the Influence of chlorpromazine hydrochloride on dimyrstoylphosphatidylcholine liposomes in different media. Int J Pharm Sci Res 2015;6:3245-53.

46. Watts A, Marsh D, Knowles PF. Characterization of DMPC vesicles and their dimensional changes through the phase transition-molecular control of membrane morphology. Biochemistry 1978;17:1792-801.

47. Kwant WO, Steveninck JV. The influence of chlorpromazine On human erythrocytes. Biochem Pharmacol 1986;17:2215-23.

48. Green AL. Ionization constants and water solubilities of some amino-alkyl-phenothiazine tranquilizers and related compounds. J Pharm Pharmac 1967;19:10-6.

49. Lee AG. Local anesthesia: the interaction between phospholipids and chlorpromazine, propranolol and practolol. Mol Pharma 1977;13:474-87.

50. Nussio Matthew R, Sykes Matthew J, Miners John O, Shapter Joseph G. Characterisation of chlorpromazine binding to lipid bilayer membranes. International Conference on Nanoscience and Nanotechnology; 2006. https://doi.org/10.1109/ ICONN.2006.340603. 